\title{
Mycobacterium Intracellulare Infection Associated with TYK2 Deficiency: A Case Report and Review of the Literature
}

\author{
Wanru Guo' \\ Xuewen Feng (D) \\ Meifang Yang' \\ Yanwan Shangguan' \\ Pei Shi ${ }^{1}$ \\ Shuting Wang' \\ Ming $\mathrm{Hu}^{\prime}$ \\ Mohamed S Draz ${ }^{2}$ \\ Kaijin Xu'
}

'State Key Laboratory for Diagnosis and Treatment of Infectious Diseases, National Clinical Research Center for Infectious Diseases, Collaborative Innovation Center for Diagnosis and Treatment of Infectious Diseases, The First Affiliated Hospital, College of Medicine, Zhejiang University, Hangzhou, People's Republic of China; ${ }^{2}$ Department of Medicine, Brigham and Women's Hospital, Harvard Medical School, Boston, MA, USA
Correspondence: Kaijin Xu Email zdyxyxkj@zju.edu.cn
This article was published in the following Dove Press journal: Infection and Drug Resistance

\begin{abstract}
Individuals with genetic defects show an increased susceptibility to poorly pathogenic mycobacteria including nontuberculous mycobacteria and Bacillus CalmetteGuerin (BCG). In previous studies, defects in multiple genes were identified to be associated with mycobacterium infection including tyrosine kinase 2 (TYK2). The mutations lead to insufficient production of interferon (IFN)- $\gamma$ or an insufficient response to IFN- $\alpha / \beta$, interleukin (IL)-6, IL-10, IL-12 and IL-23. Herein, we describe a case of Mycobacterium intracellulare infection in a male with abdominal pain and diarrhea. Whole exome sequencing of the genomes revealed a compound heterozygous mutation (c.3083A $>\mathrm{G} / \mathrm{c} .2590 \mathrm{C}>\mathrm{T}$, p.N1028S/p.R864C) in the TYK2 gene. The patient recovered after two years of antimycobacterial treatment and no relapse was observed so far. We also reviewed 24 cases of mycobacterial infection associated with TYK2 deficiency which provides evidence of how personalised genomics can improve outcomes.
\end{abstract}

Keywords: TYK2 deficiency, Mycobacterium intracellulare infection, case report, genetic testing, treatment

\section{Introduction}

Severe mycobacterial disease is more likely to occur in patients with secondary immunodeficiency due to conditions such as HIV infection, malignancy or immunosuppressive treatments or in patients with inherited defects like T-celldeficiency. ${ }^{1,2}$ However, such infections may also occur in patients with no acquired immunodeficiency. Recent studies revealed that host genetic factors can be associated with the susceptibility to and severity of mycobacterial disease. ${ }^{3-5}$ TYK2 is one of the genes that has been identified to be related to mycobacterial disease. ${ }^{6}$ TYK2 is a member of the Janus kinase (Jak) family which plays a key role in the pathways involving responses to IFN- $\alpha / \beta$, IL-6, IL-10, IL-12 and IL-23. ${ }^{7}$ Previous studies have shown that IFN- $\gamma$ production by $\mathrm{T}$ cells from TYK2-deficient patients was impaired. ${ }^{8,9}$ TYK2 mutation impairs IL-12 and IL-23 signaling, weakens the response of $\mathrm{NK}$ and $\mathrm{T}$ cells to IL-12 and IL-23, resulting in insufficient IFN- $\gamma$ production. ${ }^{3,8}$ TYK2 deficiency can lead to an increased susceptibility to mycobacterial or viral infections due to insufficient production of IFN- $\gamma$ or an insufficient response to these cytokines. Here, we present a compound heterozygous mutation in the TYK2 gene in a patient with Mycobacterium intracellulare infection. We also briefly reviewed the literature related to cases of TYK2 deficiency. 


\section{Case Report}

A 24-year-old male was referred to our hospital with symptoms of abdominal pain and diarrhea without hematochezia. The patient had previously been treated with antibiotics in a local hospital with poor treatment outcomes. Then, he had a colonoscopy that indicated colitis (tuberculosis could not be excluded). Pathology showed chronic inflammation with granulomas (Figure 1A and B). The T-SPOT test for tuberculosis infection was positive. The patient was diagnosed with intestinal tuberculosis and was treated with isoniazid, rifampicin, pyrazinamide, and ethambutol. However, his symptoms did not improve, and he came to our hospital for further treatment. The patient had no underlying disease or overt immunodeficiency. After admission, physical examination revealed fever $\left(38.5^{\circ} \mathrm{C}\right)$. Abdominal examination showed slight tenderness under the xiphoid and the left epigastric, periumbilical and right epigastric. Abdominal auscultation showed reduced bowel sounds. A chest CT scan revealed a nodular lesion in the right main bronchus (Figure 2A). An abdominal CT scan revealed a mass in the right lower abdomen (Figure 2B). Bronchoscopy was performed, which revealed mucosal infiltrate and blockage of the upper left and lower right bronchus (Figure 2C). Puncture revealed granulomatous inflammation in the left cervical
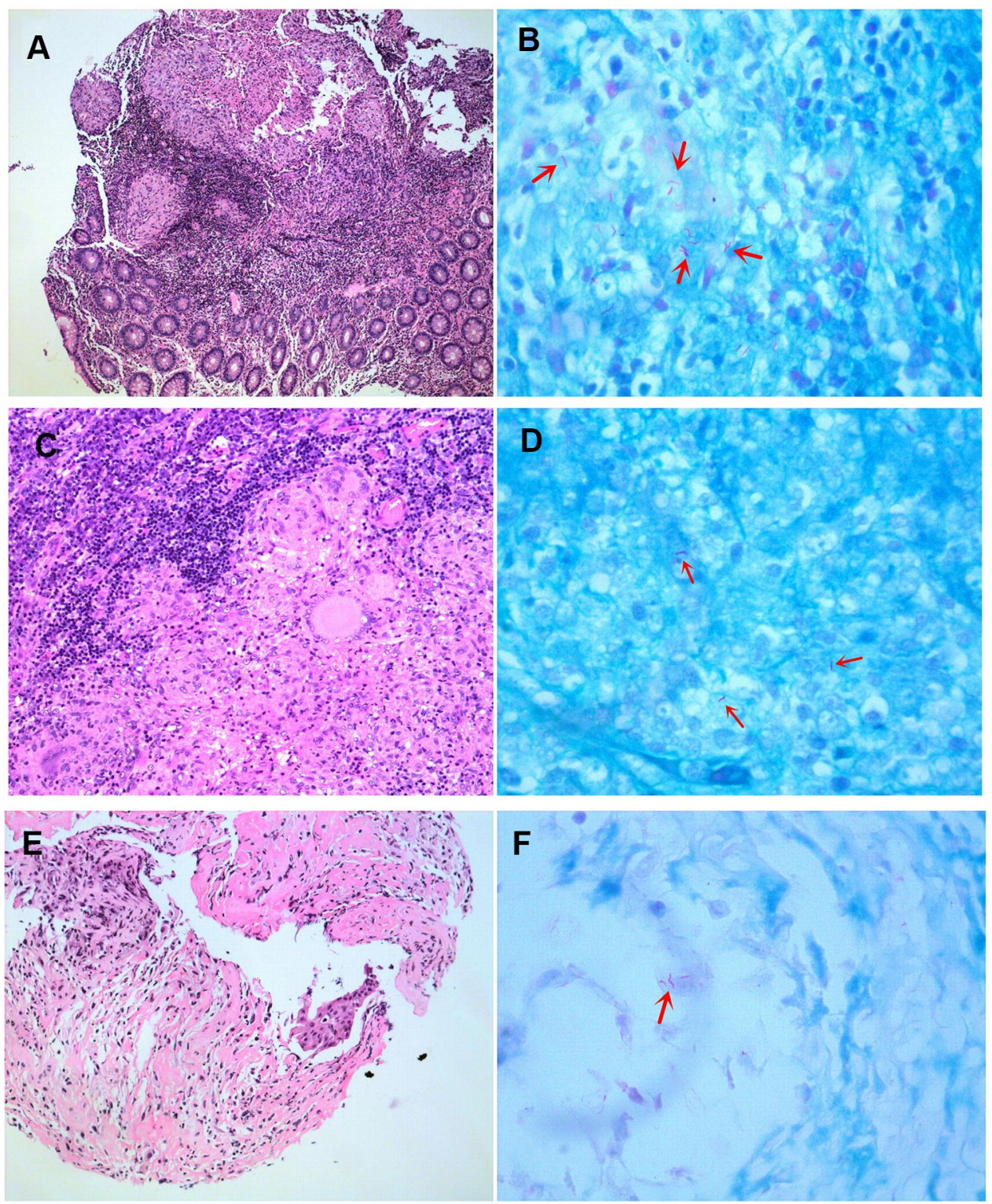

Figure I Hematoxylin and eosin stain (H\&E) of biopsy specimens. (A) Intestinal biopsy specimen revealed acid-fast bacilli. (B) Intestinal biopsy specimen showed acid-fast bacilli (arrows). (C) Lymph node biopsy specimen revealed acid-fast bacilli. (D) Lymph node biopsy specimen showed acid-fast bacilli (arrows). (E) Bronchial biopsy specimen revealed acid-fast bacilli. (F) Bronchial biopsy specimen showed acid-fast bacilli (arrow). Original magnifications: (A) I00X; (B, D and F) I000X; (C and E) 200X. 

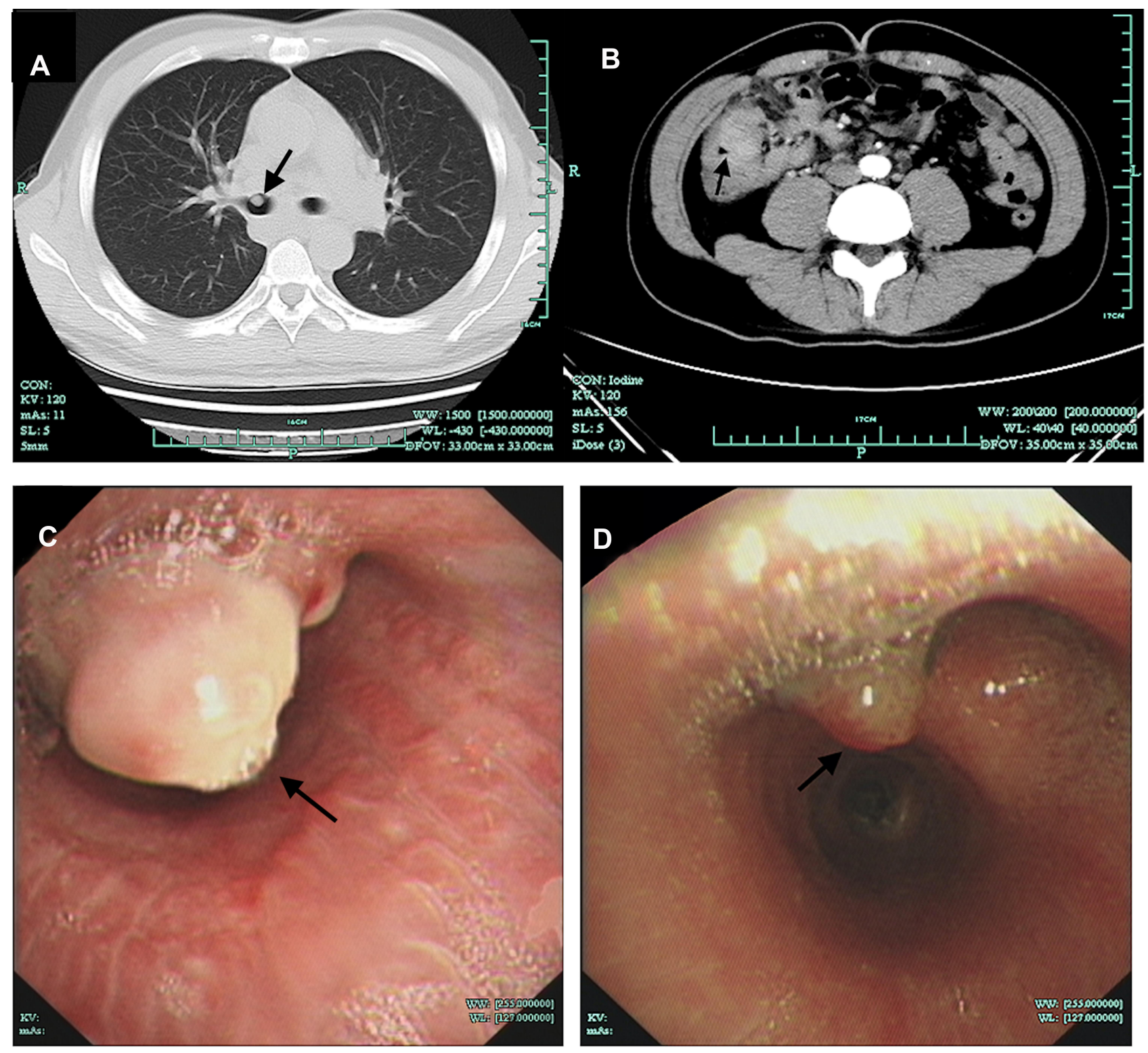

Figure 2 Computed tomography and Bronchoscopy findings. (A) Chest CT showed a nodular lesion in the right main bronchus (arrow). (B) Abdominal CT showed a mass in the right lower abdomen (arrow). (C) Bronchoscopy showed nodules in the right bronchus (arrow). (D) The nodule in the right bronchus was smaller after five months of treatment (arrow).

lymph nodes and acid-fast staining was positive (Figure 1C and D). Pathological examination of the bronchial biopsy sample revealed many acid-fast stain positive bacteria (Figure 1E and F). Biochip system can be used for species identification of mycobacterium by detecting the difference of $16 \mathrm{~S}$ rRNA sequence. ${ }^{10}$ After sample preparation, chip hybridization, washing, data acquisition and analysis, the biopsy specimen was identified as Mycobacterium intracellulare by the Biochip system.

Whole-exome sequencing (WES) is a useful tool for identifying new disease-causing genes. In this method, blood samples are used to prepare the library, and then
DNA is captured and enriched by chip, and finally, mutations are detected through a high-throughput sequencing platform. WES revealed that the patient carried compound heterozygous mutations c.3083A $>\mathrm{G} / \mathrm{c} .2590 \mathrm{C}>\mathrm{T} \quad$ (p. N1028S/p. R864C) in TYK2 (Figure 3A). We also investigated the TYK2 gene of the patient's parents by Sanger sequencing. Both parents were heterozygous and healthy (Figure 3B). The mutation c.2590C $>$ T (p. R864C) was found in his mother and the mutation c.3083A $>\mathrm{G}$ (p. N1028S) was carried by his father. The mutation c. $2590 \mathrm{C}>\mathrm{T}$ (p. R864C) was inherited maternally and c.3083A $>$ G (p.N1028S) was inherited paternally. 


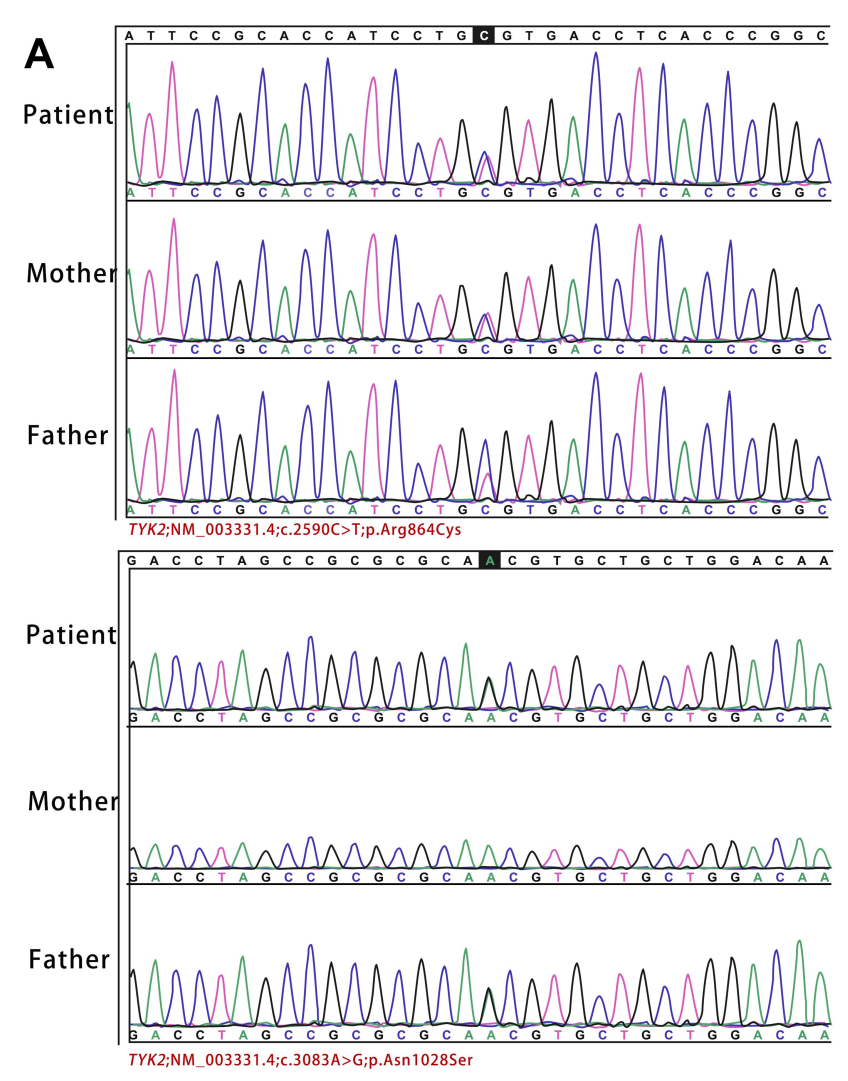

B

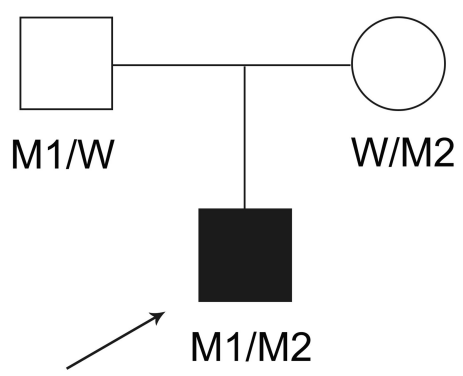

Figure 3 Identification of TYK2 compound heterozygous mutation. (A) Validation by Sanger sequencing of theTYK2 mutations in the patient and his parents. (B) Pedigree of a family in our case. Squares and circles indicate males and females, respectively. Darkened symbols represent the affected individuals. The proband is indicated by an arrow. W, wild-type; MI, c.3083A>G (p.NI028S); M2, c.2590C>T (p. R864C).

The patient was finally diagnosed with Mycobacterium intracellulare infection. Nontuberculous mycobacteria had invaded the intestine, lymph nodes and bronchi. The patient had impaired liver function, we started therapy with iproniazid, ethambutol, moxifloxacin, and linezolid, and replaced iproniazid with meropenem after diagnosis. His clinical condition showed significant improvement. The patient was discharged when his temperature became normal and the abdominal pain disappeared. Treatment with moxifloxacin, linezolid, ethambutol and faropenem was continued after discharge from hospital, which was effective and with no obvious side effects. After five months of treatment, bronchoscopy showed a narrowing of the nodule in the right bronchus (Figure 2D). The patient recovered after two years of anti-mycobacterial treatment and no relapse is observed so far.

\section{Discussion and Conclusions}

Both mutations we reported are novel, the missense mutation c.3083A $>\mathrm{G}$ (p.N1028S) leads the substitution of asparagine to serine at position 1028, affecting the pseudokinase domain of TYK2 protein. The other mutation c. $2590 \mathrm{C}>\mathrm{T}$ (p. R864C) leads the substitution of arginine to cysteine at position 864, affecting the kinase domain of TYK2 protein. TYK2 is one of the JAKs that is considered to play a crucial role in the transduction of signaling by several cytokines including IFN- $\alpha / \beta$, IL-6, IL-10, IL-12 and IL-23. ${ }^{9,11,12}$ It mediates signal transduction via the phosphorylation of signal transducer and activator of transcription (STAT) proteins. ${ }^{13}$ Each mutation may play an inhibition effect on the TYK2 gene and protein expression, which is shown to impair IL-12 and IL-23 signaling. A lack of IL-12 and IL-23 signaling results in impaired IFN- $\gamma$ production, which can eventually lead to a higher susceptibility to mycobacterial infection. ${ }^{3,14}$ Impaired responses to IFN- $\alpha / \beta$ can result in viral infections. Additionally, TYK2 is essential for the IL-6 and IL-10 signaling pathways that regulate a broad range of physiological responses. ${ }^{15}$ Although it is highly likely that the two novel TYK2 mutations we have identified lead to the mycobacterium disease in our patient, we have no formal evidence to prove it. More studies are needed to fully understand the role of these mutations in TYK2.

We searched the PubMed database for reports of TYK2 deficiency published as of June 2020 and found cases in English-language articles that included clinical details. Additional references were found by checking those quoted in the articles retrieved. Our review of the literature revealed 24 cases, including the present case (Table 1). The patients originated from different countries including Morocco, Iran, Japan, Turkey, Chile, Argentina, Kurdistan, Iran, Sweden, Mexico, Brazil, Algeria and China. They involved eighteen males and five females. The male-tofemale ratio was 19:5. The patients ranged in age from 1 to 40 years when symptoms first appeared, with the majority under 16 years old (79\%). In our review, three patients were 
Table I Summary of Demographic and Clinical Characteristics

\begin{tabular}{|c|c|c|c|c|c|c|c|c|}
\hline $\begin{array}{l}\text { Patient/ } \\
\text { Sex/Age } \\
\text { (y) }\end{array}$ & Country & $\begin{array}{l}\text { Other } \\
\text { Infections }\end{array}$ & $\begin{array}{l}\text { Bacterial } \\
\text { Infections }\end{array}$ & Mutation & $\begin{array}{l}\text { BCG } \\
\text { Vaccination }\end{array}$ & Disease & Treatment & Results \\
\hline $\mathrm{PI}^{16} / \mathrm{M} / \mathrm{I}$ & Japan & $\begin{array}{l}\text { HSV, PRV-3, } \\
\text { MCV, } \\
\text { C. albicans }\end{array}$ & BCG-itis, Salmonella & $\mathrm{C} 70 \mathrm{Hfs} \times 2 \mathrm{I}$ & Yes & HIES & I & A \\
\hline $\mathrm{P} 2{ }^{9} / \mathrm{M} / \mathrm{I}$ & Turkey & VZV & BCG-osis, Brucella & L767X & Yes & Disseminated BCG disease & $\mathrm{Ab}$ & A \\
\hline $\mathrm{P} 3^{9} / \mathrm{F} / \mathrm{I} 3$ & Morocco & No & M.tuberculosis & TII06Hfs X4 & Yes & Disseminated tuberculosis & $\mathrm{Ab}$ & $D$ \\
\hline $\mathrm{P} 4{ }^{9} / \mathrm{M} / \mathrm{I}$ & Morocco & Yes? & Yes? & TII06HfsX4 & Yes & Meningitis & No & $A$ \\
\hline $\mathrm{P} 5{ }^{9} / \mathrm{M} / \mathrm{I}$ & Iran & No & BCG-osis & EI54X & Yes & Disseminated BCG disease & $\mathrm{Ab}$ & A \\
\hline $\mathrm{P} 6{ }^{9} / \mathrm{F} / \mathrm{I}$ & Iran & Yes & BCG-itis & EI55X & Yes & BCG disease & I & A \\
\hline $\mathrm{P} 7^{9} / \mathrm{F} / 9$ & Iran & No & M.tuberculosis & S50HfsXI & Yes & Miliary tuberculosis & 1 & A \\
\hline $\mathrm{P} 8{ }^{9} / \mathrm{M} / \mathrm{I}$ & Argentina & HSV & No & R638X & Yes & Disseminated HSV disease & Acyclovir & A \\
\hline $\mathrm{P} 9^{12} / \mathrm{F} / 5$ & Kurdistan & No & No & Pro216Argfs*14 & No & HIES & 1 & $A$ \\
\hline $\begin{array}{l}\mathrm{PI} 0^{15} / \mathrm{M} / \\
12\end{array}$ & Japan & EBV & No & $\begin{array}{l}\text { Cys70Serfs*2I/ } \\
\text { R23IW }\end{array}$ & Yes & $\begin{array}{l}\text { T-cell lymphopenia, EBV- } \\
\text { associated B-cell lymphoma }\end{array}$ & $\begin{array}{l}\text { Chemotherapy, } \\
\text { BMT }\end{array}$ & $\mathrm{D}$ \\
\hline $\mathrm{PII} / 5 / \mathrm{F} / 3$ & Japan & EBV & No & $\begin{array}{l}\text { Cys70Serfs*2I/ } \\
\text { R23IW }\end{array}$ & Yes & $\begin{array}{l}\text { T-cell lymphopenia, EBV- } \\
\text { associated B-cell lymphoma }\end{array}$ & Chemotherapy & A \\
\hline $\mathrm{PI} 2^{14} / \mathrm{M} / \mathrm{I}$ & Sweden & No & $\begin{array}{l}\text { Mycobacterium } \\
\text { bovis BCG }\end{array}$ & PII04A & Yes & BCG osteomyelitis & $\mathrm{Ab}$ & A \\
\hline $\mathrm{PI} 3^{14} / \mathrm{M} / \mathrm{I}$ & Mexico & No & M.avium complex & PII04A & No & MAC osteomyelitis & $\mathrm{Ab}$ & $A$ \\
\hline $\mathrm{PI} 4^{14} / \mathrm{M} / 2$ & Iran & No & BCG-osis & PII04A & Yes & Disseminated BCG disease & $\mathrm{Ab}, \mathrm{IFN}-\gamma$ & $A$ \\
\hline $\mathrm{PI}^{14} / \mathrm{M} / 6$ & Brazil & No & M.tuberculosis & PII04A & Yes & Pulmonary tuberculosis & $\mathrm{Ab}$ & $A$ \\
\hline $\mathrm{PI} 6^{14} / \mathrm{F} / 40$ & Algeria & Aspergillus & M.tuberculosis & PII04A & Yes & Pulmonary tuberculosis & $A b$ & $A$ \\
\hline $\begin{array}{l}\mathrm{PI} 7^{14} / \mathrm{M} / \\
27\end{array}$ & Morocco & No & M.tuberculosis & PII04A & Yes & Pulmonary tuberculosis & $A b$ & $A$ \\
\hline $\begin{array}{l}\mathrm{P} 18^{14} / \mathrm{M} / \\
15\end{array}$ & turkey & No & M.tuberculosis & PII04A & Yes & Miliary tuberculosis & $A b$ & $A$ \\
\hline $\begin{array}{l}\mathrm{PI} 9^{14} / \mathrm{M} / \\
13\end{array}$ & Chile & No & M.tuberculosis & PII04A & Yes & Pulmonary tuberculosis & $A b$ & $A$ \\
\hline $\begin{array}{l}\mathrm{P} 20^{14} / \mathrm{M} / \\
35\end{array}$ & Morocco & No & M.tuberculosis & PII04A & Yes & Pulmonary tuberculosis & $A b$ & $A$ \\
\hline $\begin{array}{l}\mathrm{P} 2 \mathrm{I}^{14} / \mathrm{M} / \\
33\end{array}$ & Chile & No & M.tuberculosis & PII04A & Yes & Pulmonary tuberculosis & $A b$ & $A$ \\
\hline $\mathrm{P} 22^{17} / \mathrm{M} / \mathrm{I}$ & Iran & HSV, VZV & $\begin{array}{l}\text { Mycobacterium } \\
\text { bovis BCG }\end{array}$ & P216Rfs*14 & Yes & BCG disease & I & $A$ \\
\hline $\mathrm{P} 23^{18} / \mathrm{M} / \mathrm{I}$ & China & No & $\begin{array}{l}\text { Mycobacterium } \\
\text { bovis BCG, } \\
\text { Salmonella }\end{array}$ & G799R & Yes & BCG disease & I & $A$ \\
\hline $\begin{array}{l}\mathrm{P} 24, \text { our } \\
\text { case/M/24 }\end{array}$ & China & No & $\begin{array}{l}\text { Mycobacterium } \\
\text { intracellulare }\end{array}$ & NI028S/R864C & Yes & Disseminated NTM disease & $\mathrm{Ab}$ & $A$ \\
\hline
\end{tabular}

Abbreviations: M, male; F, female; HSV, herpes simplex virus; PRV-3, parainfluenza virus type 3; MCV, molluscum contagiosum virus; VZV, varicella zoster virus; EBV, Epstein-Barr virus; HIES, hyper-IgE syndrome; BCG, Bacillus Calmette-Guerin; IFN- $\gamma$, interferon gamma; NTM, nontuberculous mycobacteria; D, died; A, alive; Ab, antibiotic. 
confirmed to have compound heterozygous frame shift and missense TYK2 mutations, and the others were affected by homozygous TYK2 mutations. Among the previously reported patients, twenty demonstrated impaired responses to IFN- $\alpha / \beta$, IL-12, IL-23 and IL-10, but only the first patient reported (P1) displayed an impaired response to IL-6. Impaired responses to these cytokines can account for the clinical features. All patients but two ( $\mathrm{P} 9$ and $\mathrm{P} 13$ ) had been vaccinated with BCG. Eight (33\%) of them suffered from adverse reactions to BCG and developed localized or disseminated BCG disease. Nine (38\%) of them had tuberculosis, two $(8 \%)$ had non-mycobacterial disease, two $(8 \%)$ had Epstein-Barr virus (EBV)-driven lymphoproliferative diseases, two (8\%) had hyper-IgE syndrome, and the other two had meningitis and disseminated herpes simplex virus (HSV) disease. The two patients with EBV-associated B-cell lymphoma displayed approximately normal responses to IL-12, which may be why they did not develop BCG or Salmonella infections. Seven $(29 \%)$ of the 24 patients also suffered from viral infections, including diseases caused by molluscum contagiosum virus (MCV), HSV, parainfluenza virus type 3 (PRV-3), varicella zoster virus (VZV), and EBV. No lethal viral infections were observed which may have been due to residual responses to IFNs. Fourteen (58\%) patients received antimycobacterial treatment. Most of the patients were cured without recurrence, and only one patient with disseminated extrapulmonary tuberculosis died (P3), which probably occurred because IFN- $\gamma$ production was insufficient. This indicates that anti-mycobacterial treatment is effective in patients with TYK2 deficiency and other treatment measures need to be adopted for some patients with severe mycobacterial infection. Two patients with EBV-driven lymphoproliferative diseases were treated with chemotherapy or allogeneic bone marrow transplantation: one died during treatment and the other survived.

Severe mycobacterial disease is difficult to cure and can even lead to death. Genetic testing can help to identify individuals at high risk and provide more precise diagnosis and control. At present, the majority of patients with mycobacterial disease are treated with antibiotics. It has been reported that patient with TYK2 mutation recovered after treatment with antibiotics and IFN- $\gamma,{ }^{9}$ so it is probably beneficial for patients to be treated with injected recombinant IFN- $\gamma$ if their IFN- $\gamma$ production is insufficient and their response to IFN- $\gamma$ is not abolished. ${ }^{19,20}$ In our study, we did not confirm whether our patient had impaired IFN- $\gamma$ production. The patient in our case responded well to combinational antibiotic therapy, so recombinant IFN- $\gamma$ treatment was not considered. Transduction of the intact TYK2 gene was also reported to rescue the patient's cells from the cytokine signaling defects, ${ }^{16}$ which may be a new option for treatment. Thus, for patients with severe mycobacterial disease, genetic testing should be adopted when necessary to aid in exploring pathogenesis and to determine further treatment.

Genetic testing can also be used to provide genetic counseling for families. Much progress has been made in understanding the genetic predisposition to mycobacterial disease, but the mechanisms remain elusive and many questions remained unanswered: (i) what is the prevalence of genetic-related mycobacterial disease? (ii) how significant the role of gene deficiency in the mycobacterial disease development? It is necessary to conduct further studies to clarify the relationship between genetic variants and mycobacterial infection, which can be significantly important to consider in clinical practice in the future.

\section{Abbreviations}

BCG, Bacillus Calmette-Guerin; TYK2, tyrosine kinase 2; IFN, interferon; IL, interleukin; Jak, Janus kinase; WES, whole-exome sequencing; STAT, signal transducer and activator of transcription; EBV, Epstein-Barr virus; HSV, herpes simplex virus; MCV, molluscum contagiosum virus; PRV-3, parainfluenza virus type $3 ; \mathrm{VZV}$, varicella zoster virus.

\section{Ethics and Consent Statement}

Written informed consent was provided by the patient to allow the case details and any accompanying images to be published, the patient's parents also provided consent regarding the genetic tests, and this report was approved by the Ethical Committee of the First Affiliated Hospital, School of Medicine, Zhejiang University (reference number is 2020-604).

\section{Acknowledgments}

We would like to thank the patient for his contribution.

\section{Disclosure}

The authors declare that they have no conflicts of interest in this work.

\section{References}

1. Haverkamp MH, van de Vosse E, van Dissel JT. Nontuberculous mycobacterial infections in children with inborn errors of the immune system. $J$ Infect. 2014;68(Suppl 1):S134-150. doi:10.1016/j.jinf. 2013.09.024 
2. Dávila Saldaña BJ, Keller M, Hanisch BR, Song X. Tap water: a possible source of nontuberculous mycobacterial infection in patients with T cell deficiency. Am J Infect Control. 2019;47 (7):834-836. doi:10.1016/j.ajic.2018.10.016

3. Patel SY, Doffinger R, Barcenas-Morales G, Kumararatne DS. Genetically determined susceptibility to mycobacterial infection. J Clin Pathol. 2008;61(9):1006-1012. doi:10.1136/jcp.2007.051201

4. Abel L, Fellay J, Haas DW, et al. Genetics of human susceptibility to active and latent tuberculosis: present knowledge and future perspectives. Lancet Infect Dis. 2018;18(3):e64-e75. doi:10.1016/ S1473-3099(17)30623-0

5. Cai L, Li Z, Guan X, et al. The research progress of host genes and tuberculosis susceptibility. Oxid Med Cell Longev. 2019;2019:9273056. doi:10.1155/2019/9273056

6. Rosain J, Kong XF, Martinez-Barricarte R, et al. Mendelian susceptibility to mycobacterial disease: 2014-2018 update. Immunol Cell Biol. 2019;97(4):360-367. doi:10.1111/imcb.12210

7. Wöss K, Simonović N, Strobl B, Macho-Maschler S, Müller M. TYK2: an upstream kinase of STATs in cancer. Cancers. 2019;11 (11):11. doi:10.3390/cancers 11111728

8. van de Vosse E, Ottenhoff TH. Human host genetic factors in mycobacterial and salmonella infection: lessons from single gene disorders in IL-12/IL-23-dependent signaling that affect innate and adaptive immunity. Microbes Infect. 2006;8(4):1167-1173. doi:10.1016/j. micinf.2005.10.032

9. Kreins AY, Ciancanelli MJ, Okada S, et al. Human TYK2 deficiency: mycobacterial and viral infections without hyper-IgE syndrome. $J$ Exp Med. 2015;212(10):1641-1662. doi:10.1084/jem.20140280

10. Zhu L, Jiang G, Wang S, et al. Biochip system for rapid and accurate identification of mycobacterial species from isolates and sputum. J Clin Microbiol. 2010;48(10):3654-3660. doi:10.1128/JCM.00158-10

11. Silvennoinen O, Ihle JN, Schlessinger J, Levy DE. Interferon-induced nuclear signalling by Jak protein tyrosine kinases. Nature. 1993;366 (6455):583-585. doi:10.1038/366583a0
12. Fuchs S, Kaiser-Labusch P, Bank J, et al. Tyrosine kinase 2 is not limiting human antiviral type III interferon responses. Eur J Immunol. 2016;46(11):2639-2649. doi:10.1002/eji.201646519

13. Karjalainen A, Shoebridge S, Krunic M, et al. TYK2 in tumor immunosurveillance. Cancers. 2020;12(1):1. doi:10.3390/cancers 12010150

14. Boisson-Dupuis S, Ramirez-Alejo N, Li Z, et al. Tuberculosis and impaired IL-23-dependent IFN- $\gamma$ immunity in humans homozygous for a common TYK2 missense variant. Sci Immunol. 2018;3(30):30. doi:10.1126/sciimmunol.aau8714

15. Nemoto M, Hattori H, Maeda N, et al. Compound heterozygous TYK2 mutations underlie primary immunodeficiency with T-cell lymphopenia. Sci Rep. 2018;8(1):6956. doi:10.1038/s41598-01825260-8

16. Minegishi Y, Saito M, Morio T, et al. Human tyrosine kinase 2 deficiency reveals its requisite roles in multiple cytokine signals involved in innate and acquired immunity. Immunity. 2006;25 (5):745-755. doi:10.1016/j.immuni.2006.09.009

17. Sarrafzadeh SA, Mahloojirad M, Casanova JL, et al. A new patient with inherited TYK2 deficiency. J Clin Immunol. 2020;40 (1):232-235. doi:10.1007/s10875-019-00713-5

18. Wu P, Chen S, Wu B, Chen J, Lv G. A TYK2 gene mutation c. $2395 \mathrm{G}>\mathrm{A}$ leads to TYK2 deficiency: a case report and literature review. Front Pediatr. 2020;8:253. doi:10.3389/fped.2020.00253

19. Bustamante J, Boisson-Dupuis S, Abel L, Casanova JL. Mendelian susceptibility to mycobacterial disease: genetic, immunological, and clinical features of inborn errors of IFN- $\gamma$ immunity. Semin Immunol. 2014;26(6):454-470. doi:10.1016/j.smim.2014.09.008

20. Boisson-Dupuis S. The monogenic basis of human tuberculosis. Hum Genet. 2020;139(6-7):1001-1009.
Infection and Drug Resistance

\section{Publish your work in this journal}

Infection and Drug Resistance is an international, peer-reviewed openaccess journal that focuses on the optimal treatment of infection (bacterial, fungal and viral) and the development and institution of preventive strategies to minimize the development and spread of resistance. The journal is specifically concerned with the epidemiology of

\section{Dovepress}

antibiotic resistance and the mechanisms of resistance development and diffusion in both hospitals and the community. The manuscript management system is completely online and includes a very quick and fair peerreview system, which is all easy to use. Visit http://www.dovepress.com/ testimonials.php to read real quotes from published authors. 